\title{
Characterization of phenolic compounds and antioxidant activity of ethanolic extracts from flowers of Andryala glandulosa ssp. varia (Lowe ex DC.) R.Fern., an endemic species of Macaronesia region
}

\author{
Sandra Gouveia, João Gonçalves, Paula C. Castilho* \\ Centro de Química da Madeira, CCCEE, Universidade da Madeira, Campus Universitário da Penteada, piso 0, 9000-390 Funchal, Portugal
}

\section{A R T I C L E I N F O}

\section{Article history:}

Received 26 February 2012

Received in revised form 24 June 2012

Accepted 26 June 2012

\section{Keywords:}

Asteraceae

Andryala

Polyphenols

Antioxidant activity

HPLC-DAD-ESI/MS ${ }^{n}$

\begin{abstract}
A B S T R A C T
Andryala glandulosa spp. varia (Lowe ex DC.) R.Fern. (Asteraceae), is a small shrub that grows in mountains of Madeira Island, Fuerteventura and Lanzarote from Canary Islands. The flowerheads are used traditionally for the treatment of edemas and in homemade dermo-cosmetic preparations.

In this paper the chemical composition of the extracts of this plant, used in folk medicine, and their antioxidant capacity were established; the presence of potentially harmful lactones, so commonly associated with related species used for the same purposes was also evaluated. A reversed-phase highperformance liquid chromatography method (RP-HPLC) coupled with diode-array detection (DAD) and electrospray ionization mass spectrometry $\left(\mathrm{ESI} / \mathrm{MS}^{n}\right)$ was used for the characterization of phenolic compounds in ethanol extracts of flowers from A. glandulosa spp. varia collected in Madeira Island. Total phenolic content (TPC) and total flavonoid content (TFC) were established and three assays (DPPH, ABTS and FRAP) were used to measure the antioxidant capacity of the dichloromethane and ethanol extracts.

The dichloromethane extract of $A$. glandulosa contain long linear chain hydrocarbons and esters. In the alcoholic extracts, a total of 16 compounds were characterized based on their UV, mass spectra and HPLC retention time. Quinic acid and luteolin derivatives were found to be the main compounds. Quantification of caffeoylquinic acids (CQA) detected was performed by HPLC-DAD and 5-O-CQA and 3,5-O-diCQA were the major compounds (with values of $22.40 \pm 0.21$ and $59.69 \pm 1.07 \mathrm{mg} / 100 \mathrm{~g}$ dried plant, respectively). Only the ethanol extract was active, revealing a high radical scavenging capacity and a moderate reducing potential.

The potent antioxidant alcoholic extracts are composed mainly of hydroxycinnamic acid derivatives and flavonoids. The presence of sesquiterpene lactones was not detected. Since lactones are very common among related plants, like arnicas, and known to cause dermatitis and other unwanted effects, this can be an explanation for the preference for Andryala over other more easily available alternatives.
\end{abstract}

(c) 2012 Elsevier B.V. All rights reserved.

\section{Introduction}

Andryala glandulosa spp. varia (Lowe ex DC.) R.Fern., or Downy Sow Thistle, belongs to the family of Asteraceae and is endemic to the archipelagos of Madeira and Canary (Macaronesia Region). This is an herbaceous plant with lanceolate basal leaves and yellowgolden flowers, which occur usually in open places of medium to high altitude (Turland, 1994; Vieira, 1992). The genus Andryala L., native of the Mediterranean region, was nested within Hieracium subgenus Pilosella and has genetic relationships with Crepis L. (Gaskin and Wilson, 2007).

\footnotetext{
* Corresponding author. Tel.: +351 291705102; fax: +351 291705149.

E-mail addresses: alixstone@gmail.com, castilho@uma.pt, marguinha@gmail.com (P.C. Castilho).
}

Based on field survey, we found out that infusions of the flowers are used in the traditional folk medicine in different formulations. For example, they are used as compresses and washes for inflammation and in hydroalcoholic macerations as antiseptic for wounds. Poultices of the boiled flowers are used as an emollient for spots and to reduce edemas and hematomas.

The same use is given to the flowers of several endemic subspecies of Crepis such as (Crepis divaricata (Lowe) F. W. Schultz, Crepis vesicaria L. ssp. andryaloides and Crepis noronhaea Babc.) and also to Arnica montana (introduced species), collectively identified as "arnica flowers" (Jardim and Sequeira, 2008).

The phenolic composition of the genus Andryala has been poorly studied, as opposed to Crepis or Arnica, for which a large body of analytical data is available (Kisiel and Michalska, 2001; Zidorn et al., 2008); some studies (Stanojević et al., 2009) on Hieracium are available. The few studies relating to Andryala species, chemical 
composition concern mostly to their content in sesquiterpene lactones (STL) on the non-polar extracts (Marco et al., 1994). STL are fairly common in Asteraceae aerial parts and are associated with a variety of beneficial biological effects; however they can cause allergic reactions and can be very toxic in high doses.

Phenolic compounds are a class of low molecular weight secondary plant metabolites. Most of these compounds are able to scavenge free radicals such as those produced during cell metabolism (reactive oxygen species (ROS) or free radicals such as hydrogen peroxide, hydroxyl radical and singlet oxygen) that can lead to oxidative stress. Oxidative stress is associated with major chronic health problems like cancer, inflammation, neurodegeneration diseases, heart diseases, aging and also food deterioration (Tsao and Deng, 2004).

Special attention has been paid to plants because they are very rich sources of phenolic compounds.

High performance liquid chromatography coupled with a photodiode-array detector (HPLC-DAD) and with mass spectrometry operating with an electrospray ionization (ESI) source, is an excellent and economical tool for the efficient screening and identification of the main phenolic compounds of plant extracts.

In this work the phenolic composition of the ethanolic extracts of flowers from A. glandulosa spp. varia was established by HPLCDAD-ESI/MS ${ }^{n}$ and the dichloromethane extract was analyzed by GC-MS and FTIR in perusal for STLs.

In addition, the total phenolic and flavonoid contents of the methanol extracts were determined and correlated with the antioxidant capacity established by three different methods (DPPH, ABTS and FRAP assays).

\section{Materials and methods}

\subsection{Chemical reagents}

The following reagents were purchased from Merck (Darmstadt, Germany): potassium persulfate (99\%), sodium chloride (99.5\%), disodium phosphate dodecahydrated (99\%), glacial acetic acid (100\%), sodium carbonate (p.a.) and ferrous sulfate heptahydrate (99\%). 2,2-diphenyl-1-picrylhydrazyl (DPPH) (>95\%), Trolox ( $\geq 99.8 \%$, HPLC), 2,2'azinobis-(3-ethylbenzthiazoline-6sulfonic acid) (ABTS) ( $\geq 99 \%$, HPLC), 2,4,6-Tri(2-Pyridyl)-s-triazine (TPTZ) ( $\geq 99.0 \%$, TLC), $\beta$-carotene ( $\geq 97 \%$, UV), Tween 40 and FolinCiocalteu's phenol reagent were purchased from Fluka (Lisbon, Portugal). Potassium chloride $(>99.5 \%)$, gallic acid (99\%, HPLC), potassium acetate (p.a.), rutin ( $\geq 98 \%$, HPLC) and ferric chloride hexahydrate (97-100\%) were purchased from Panreac (Barcelona, Spain); potassium dihydrogen phosphate (99.5\%), aluminium chloride $(98 \%)$ and sodium acetate trihydrate (pure) were purchased from Riedel-de Haën (Hanover, Germany).

All solvents used for plant extraction were AR grade, purchased from Fisher (Lisbon, Portugal). HPLC-MS grade acetonitrile (99.9\%, LabScan, Gliwice, Poland) and ultra-pure water (Milli-Q Waters purification system, EUA) were used for HPLC analysis.

Stock solutions of standard compounds $(100 \mu \mathrm{g} / \mathrm{mL})$ were prepared in ethanol for HPLC-DAD-ESI/MS ${ }^{n}$ identification and stored in a refrigerator at $-20^{\circ} \mathrm{C}$ until use. Standards used: caffeic acid ( $>99 \%)$, luteolin ( $>99 \%)$ from Extrasynthese (Lyon, France) and 5-O-caffeoylquinic acid (99\%) from Acros Organics (Geel, Belgium). 1,3-O-dicaffeoylquinic acid, 1,5-O-dicaffeoylquinic acid, 3,4-O-dicaffeoylquinic acid, 3,5-O-dicaffeoylquinic acid, 4,5$O$-dicaffeoylquinic acid and 3,4,5-O-tricaffeoylquinic acid ( $>98 \%$ by HPLC for all) were obtained from Chengdo Biopurify Phytochemicals, Ltd. China (Sichuan, China).

\subsection{Plant material}

The flowers of $A$. glandulosa spp. varia were collected in the wild in Madeira Island, in July 2008 and July 2009, at Pico Grande, at an altitude over $1800 \mathrm{~m}$. They were identified by taxonomist Fátima Rocha and vouchers were deposited in the Madeira Botanical Garden Herbarium collection.

\subsection{Extraction procedure}

Fresh flowers of A. glandulosa (450g) were extracted with dichloromethane $(2.5 \mathrm{~L})$ during $10 \mathrm{~min}$, at room temperature. The solution was filtered and concentrated to dryness under reduced pressure in a rotary evaporator $\left(40^{\circ} \mathrm{C}\right)$, yielding $2.60 \mathrm{~g}$ of a semisolid whitish dried extract.

After this first extraction, the flowers were dried, at room temperature, and mill powered.

The flower powder obtained $(111 \mathrm{~g})$ was macerated in ethanol $(2 \times 1 \mathrm{~L})$, at room temperature for $48 \mathrm{~h}$. The extract was decolorized with activated charcoal, filtered and concentrated under reduced pressure in a rotary evaporator $\left(40^{\circ} \mathrm{C}\right)$, to give $28.0 \mathrm{~g}$ of a dark yellow oil.

\subsection{Lactones determination in dichloromethane extract}

\subsubsection{TLC analysis}

Analytical TLC was performed on silica gel 60 plates, developed with chloroform as eluent and visualized by UV ( $\lambda_{\max } 254$ and $366 \mathrm{~nm}$ ) and by spraying with Liebermann-Bouchard reagent, with negative response.

\subsubsection{GC-MS analysis}

The GC-MS analysis for identification of compounds was carried out in a Varian Saturn 3 GC-MS (Ion trap) operating in EI mode and using a HP-5MS column $(30 \mathrm{~m} \times 0.25 \mathrm{~mm}, 0.25 \mu \mathrm{m}$ film thickness), carrier gas helium, constant pressure $90 \mathrm{kPa}$, split 1:20. The oven was programmed initially from $70^{\circ} \mathrm{C}$ with 2 min hold up time to the final temperature of $230^{\circ} \mathrm{C}$ with $5^{\circ} \mathrm{C} / \mathrm{min}$ ramp. The final temperature hold time was $5 \mathrm{~min}$. The inlet and GC/MS interface temperatures were kept at $250^{\circ} \mathrm{C}$ and $280^{\circ} \mathrm{C}$, respectively. The temperature of $\mathrm{El} 70 \mathrm{eV}$ source was $200^{\circ} \mathrm{C}$ with full scan $(25-450 \mathrm{~m} / \mathrm{z})$, scan time $0.3 \mathrm{~s}$. The mass spectra of extract components were identified by comparing the mass spectra of the analytes with those of authentic standards from the mass spectra of Wiley 6.0 and Mass Spectra Library (NIST 98).

\subsubsection{FTIR}

Qualitative FTIR analysis of the dichloromethane extract was performed using a Nicolet Avatar 360 instrument operating in transmission mode within the $4000-400 \mathrm{~cm}^{-1}$ interval, with a resolution of $2 \mathrm{~cm}^{-1}$, accumulating 64 spectra, semi-solid samples were deposited over $\mathrm{KBr}$ cell windows.

\subsection{Phenolic composition of ethanol extract by HPLC-DAD-ESI/MS}

\subsubsection{Sample preparation}

Ethanolic extracts were analyzed by HPLC-DAD-ESI/MS ${ }^{n}$. For this experiment, a stock solution with concentration $(w / v)$ of $5 \mathrm{mg} / \mathrm{mL}$ was prepared by dissolving the extract in initial mobile phase $\left(\mathrm{ACN}-\mathrm{H}_{2} \mathrm{O}(20: 80)\right)$. This solution was filtered through $0.45 \mu \mathrm{m}$ Nylon micropore membranes prior to use. Three assays were performed by injecting aliquots of $10 \mu \mathrm{L}$ in the HPLC-MS system. 


\subsubsection{Liquid chromatography}

The HPLC analysis was performed on a Dionex ultimate 3000 series instrument (California, EUA) coupled to a binary pump, a diode-array detector (DAD), an autosampler and a column compartment.

Samples were separated on a Phenomenex Gemini $\mathrm{C}_{18}$ column ( $5 \mu \mathrm{m}, 250 \times 3.0 \mathrm{~mm}$ i.d.; Phenomenex) with a sample injection volume of $10 \mu \mathrm{L}$. The mobile phase was mixtures of acetonitrile (A) and water/formic acid (100/0.1, v/v) (B). A gradient program was used as follows: $20 \% \mathrm{~A}(0 \mathrm{~min}), 25 \% \mathrm{~A}(10 \mathrm{~min}), 25 \% \mathrm{~A}(20 \mathrm{~min})$, $50 \% \mathrm{~A}$ (40 min), $100 \% \mathrm{~A}$ (42-47 min), 20\% A (49-55 min). The mobile phase flow rate was $0.4 \mathrm{~mL} / \mathrm{min}$; the chromatogram was recorded at $280 \mathrm{~nm}$ and $350 \mathrm{~nm}$ and spectral data for all peaks were accumulated in the range of $190-400 \mathrm{~nm}$. Column temperature was controlled at $30^{\circ} \mathrm{C}$.

\subsubsection{HPLC-UV-DAD quantification}

The analysis was performed with the HPLC system described above using a modified gradient that allowed for the separation of all detected caffeoylquinic acid isomers. The mobile phase consisted of acetonitrile:formic acid (100:0.1,v/v) (A) and water:formic acid $(100: 0.1, v / v)(B)$. The gradient program was used as follows: $20 \%$ B (0-1 min), 78\% B (8-10 min), 76\% B (12-14 min), 75\% B (16-18 min ), 73\% B (20 min), 50\% B (40 min), 0\% B (41-45 min), and $80 \% \mathrm{~B}$ (46-50 min). The flow rate was $0.4 \mathrm{~mL} / \mathrm{min}$ and the injections volume $10 \mu \mathrm{L}$. UV detection was performed at $320 \mathrm{~nm}$.

\subsubsection{Mass spectrometry}

For HPLC-ESI/MS ${ }^{n}$ analysis, the Dionex HPLC system describe before was coupled with a Bruker Esquire (Bremen, Germany) model 6000 ion trap mass spectrometer fitted with an ESI source. Data acquisition and processing were performed using Esquire control software. Negative ion mass spectra of the column eluate were recorded in the range $m / z 100-1000$ at a scan speed of $13,000 \mathrm{Da} / \mathrm{s}$. High purity nitrogen $\left(\mathrm{N}_{2}\right)$ was used both as drying gas at a flow $10.0 \mathrm{~mL} / \mathrm{min}$ and as a nebulizing gas at pressure of $50 \mathrm{psi}$. The nebulizer temperature was set at $365^{\circ} \mathrm{C}$ and a potential of $+4500 \mathrm{~V}$ was used on the capillary. Ultra-high purity helium (He) was used as collision gas at a pressure of $1 \times 10^{-5} \mathrm{mbar}$ and the collision energy was set at $40 \mathrm{~V}$.

The acquisition of MS ${ }^{n}$ data was made with auto $M S^{n}$ mode, with isolation width of $4.0 \mathrm{~m} / z$. For $\mathrm{MS}^{n}$ analysis, mass spectrometer was scanned from 10 to $1000 \mathrm{~m} / z$ with fragmentation amplitude of $1.0 \mathrm{~V}$ and two precursor ions.

\subsection{Total phenolic compounds}

The content of phenolic compounds of the extracts was determined following the Folin-Ciocalteu method (Zheng and Wang, 2001 ) with some modifications and using gallic acid as standard. For the calibration curve, $50 \mu \mathrm{L}$ aliquots of $0.024,0.075,0.105$, 0.3 and $0.4 \mathrm{mg} / \mathrm{mL}$ gallic acid solutions in methanol were mixed with $1.25 \mathrm{~mL}$ of Folin-Ciocalteu reagent (diluted ten-fold) and $1 \mathrm{~mL}$ of sodium carbonate solution $(7.5 \mathrm{~g} / \mathrm{L}) .50 \mu \mathrm{L}$ of methanolic extract solution $(10 \mathrm{mg} / \mathrm{mL})$ were mixed with the same reagents as described above. After incubation for $30 \mathrm{~min}$ the absorbance was read at $765 \mathrm{~nm}$. The final results were expressed as gallic acid equivalents per $100 \mathrm{~g}$ of plant (mg GAE/100 g).

\subsection{Total flavonoid content}

Total flavonoid content was measured using a modified method (Akkol et al., 2008). $10 \mathrm{mg}$ of extract was dissolved in $5 \mathrm{~mL}$ of methanol. In a $10 \mathrm{~mL}$ test tube, $0.5 \mathrm{~mL}$ of sample solution, $1.5 \mathrm{~mL}$ of methanol, $2.8 \mathrm{~mL}$ of water, $0.1 \mathrm{~mL}$ of potassium acetate $(1 \mathrm{M})$ and $0.1 \mathrm{~mL}$ of aluminium chloride (10\% in methanol) were mixed. The decrease in absorbance was measured at $415 \mathrm{~nm}$ after incubation at room temperature for $30 \mathrm{~min}$. The total flavonoid content was expressed as milligrams of rutin equivalent per $100 \mathrm{~g}$ of plant ( $\mathrm{mg}$ RUE/100 g).

\subsection{Measurement of the antioxidant activity}

All UV/Vis absorptions measurements were performed on a PerkinElmer UV-Vis spectrometer Lambda 2 equipped with a water thermostatic cell holder. Glass cells with a $1 \mathrm{~cm}$ optical path were used.

\subsubsection{ABTS $^{\bullet+}$ radical cation decolorization assay}

The antioxidant activity by the method of decolorization of free radical $\mathrm{ABTS}^{\bullet+}$ was determined as previously reported (Gouveia and Castilho, 2012).

The plant extracts were dissolved in methanol to yield a concentration of $1 \mathrm{mg} / \mathrm{mL}$. For each analysis, an aliquot of $100 \mu \mathrm{L}$ methanolic solution was added to $1.8 \mathrm{~mL}$ of $\mathrm{ABTS}^{\bullet+}$ solution and the decrease of absorbance, at $\lambda=734 \mathrm{~nm}$, was recorded during $6 \mathrm{~min}$. Results were expressed in terms of $\mu$ mol Trolox equivalent per $100 \mathrm{~g}$ of plant antioxidant capacity ( $\mu$ mol eq. Trolox/100 g plant).

\subsubsection{DPPH radical scavenging activity}

The antioxidant activity by DPPH method was determined according to (Atoui et al., 2005) with some modifications (Gouveia and Castilho, 2011).

The DPPH radical scavenging effect of the extracts was expressed, based on the Trolox calibration curve, as $\mu$ mol Trolox equivalent per $100 \mathrm{~g}$ of plant ( $\mu \mathrm{mol}$ eq. Trolox/100 $\mathrm{g}$ plant).

\subsubsection{Ferric reducing antioxidant power (FRAP) assay}

The FRAP assay, as described by (Benzie and Strain, 1996), was performed with some adjustments as described in our recent paper (Gouveia and Castilho, 2012).

The extracts were dissolved in methanol to yield a final concentration of $1 \mathrm{mg} / \mathrm{mL}$. For each analysis, $30 \mu \mathrm{L}$ of methanolic solution were added to $180 \mu \mathrm{L}$ of distilled water and $1.8 \mathrm{~mL}$ of FRAP solution. The absorbance of the reaction mixture was recorded at $593 \mathrm{~nm}$ in $15 \mathrm{~s}$ intervals, during $30 \mathrm{~min}$ against methanol as blank. The FRAP results were expressed as mmol Iron(II) sulfate heptahydrate per mg of plant (mmol Fe(II)/mg plant).

\subsection{Statistical analysis}

All measurements were performed in triplicate and results are expressed as mean \pm SD.

Significant differences in antioxidant activity, total phenolic and flavonoid content of the different extracts were determined using one-way ANOVA. The statistical probability was considered to be significantly different at the level of $p<0.05$.

\section{Results and discussion}

\subsection{TLC, FTIR and GC-MS analysis}

The dichloromethane extract was analyzed by TLC, FTIR and GC-MS. The chromatogram obtained in the described conditions showed 4 peaks: two intense ones with very similar mass spectra, without a distinct molecular ion and clusters at intervals of 14 mass units, characteristic of long straight chain hydrocarbons and as such identified by the NIST database; the other two (small) peaks also showed similar mass spectra with clusters at intervals of 14 mass units, with a prominent peak at $\mathrm{C}_{n} \mathrm{H}_{2 n-1} \mathrm{O}_{2}{ }^{+}$in each cluster and a base peak at $m / z 88$, a diagnostic peak for ethyl esters. FTIR spectra of the extract showed $\mathrm{sp}^{3} \mathrm{C}-\mathrm{H}$ bands as the main 
features with a medium intensity $\mathrm{C}=\mathrm{O}$ band at $1731 \mathrm{~cm}^{-1}$ and moderate $\mathrm{C}-\mathrm{O}$ band at $1460 \mathrm{~cm}^{-1}$. This is consistent with the GC-MS results, with hydrocarbons being more abundant that esters. The spectra did not show the characteristic lactone band at around $1760 \mathrm{~cm}^{-1}$, thus confirming the TLC data (negative response to the Liebermann-Burchard reagent) No lactones were detected, so this extract of surface components was no longer considered of interest.

\subsection{HPLC-DAD-ESI/MS ${ }^{n}$ analysis}

The high antioxidant capacity and phenolic content of the ethanolic extract led us to investigate the phenolic profile of this extract by HPLC-DAD-ESI/MS ${ }^{n}$.

Three independent assays were performed for the analysis of the ethanolic extract from A. glandulosa by HPLC-DAD-ESI/MS ${ }^{n}$ and no relevant variation was noticed that can be related to the nature of detected fragments and their relative intensities.

The base peak chromatogram (BPC) profile of ethanolic extract is shown in Fig. 1 and, as can been seen, the majority of the compounds could be well separated.

Whenever it was possible the detected compounds were compared with reference. For unknown compounds, their structures were thus characterized based mainly on their $\mathrm{MS}^{n}$ fragmentation behavior, on HPLC retention times and on studies of their UV spectra.

Different types of compounds showed different UV absorption characteristics bands. Hydroxycinnamic acid derivatives showed two maximum absorption bands at $230-240 \mathrm{~nm}$ and $320-330 \mathrm{~nm}$, with a shoulder around $300-310 \mathrm{~nm}$. Peaks corresponding to flavones glycosides show three absorptions at $210-230 \mathrm{~nm}$, 250-280 $\mathrm{nm}$ and 330-350 nm. Typical flavonols spectrum exhibit two maxima absorptions at 250-295 nm and 310-370 nm, derived from the aglycone A and B rings, respectively (Gouveia and Castilho, 2009). However, different substitutions of the hydroxyl groups led to alteration in wavelength and relative intensities of these maxima (Olsen et al., 2009).

$\mathrm{MS}^{n}$ fragmentation ions of the 16 compounds detected in ethanolic extract are given in Table 1 and their chemical structures are shown in Fig. 2.

Most of the phenolic compounds detected gave deprotonated molecular ions $[\mathrm{M}-\mathrm{H}]^{-}$of high abundance, which allowed them to be analyzed by tandem MS ${ }^{n}$ fragmentation.

\subsubsection{Identification of hydroxycinnamic acid derivatives $(\mathbf{1}, \mathbf{4}, \mathbf{5}$, \\ 10 and 11)}

Five hydroxycinnamic acid derivatives were identified by HPLCDAD-ESI/MS ${ }^{n}$. The deprotonated molecular ions, $[\mathrm{M}-\mathrm{H}]^{-}$, were abundantly produced under the MS ${ }^{n}$ conditions for all hydroxycinnamic acid derivatives and the loss of the substitution groups is always referred to this ion.

Compound 1 occurred at retention time of $3.0 \mathrm{~min}$ and exhibited a $[\mathrm{M}-\mathrm{H}]^{-}$ion at $m / z 499$ and corresponds to a quinic acid derivative. In the $\mathrm{MS}^{2}$ spectrum the base peak is a fragment ion at $\mathrm{m} / \mathrm{z}$ 191 [quinic acid-H] ${ }^{-}$formed due to the loss of a 308 Da moiety. This moiety can possibly be composed of a caffeoyl group (162 Da) and a coumaroyl group (146 Da). The possibility of hexoside and rhamnose groups was excluded due to the low retention time. The loss of $146 \mathrm{Da}$ was evidenced by the formation of a fragment ion at $\mathrm{m} / \mathrm{z} 353$ (ca. $13 \%$ of base peak) as showed in Fig. 3 .

These facts suggest that the two groups should be linked in the same $-\mathrm{OH}$ group of quinic acid and the coumaroyl group must be linked to the caffeoyl group. The linkage position of acyl groups in the quinic acid can be determined by the analysis of the $[\mathrm{M}-\mathrm{H}]^{-}$ ion $\mathrm{MS}^{2}$ fragmentation.
When the acyl group is connected to a $3-\mathrm{OH}$ or $5-\mathrm{OH}$ position in quinic acid, the [quinic acid-H] ${ }^{-}$ion at $m / z 191$ is the base peak in $\mathrm{MS}^{2}$ spectrum. The [caffeic acid-H] $]^{-}$ion at $m / z 179$ is more significant for 3-O-caffeoylquinic acids, while for 5-O-caffeoylquinic acid it is very weak $(<5 \%)$ or undetectable. When the acyl group is linked to the $4-\mathrm{OH}$, the [quinic acid $\left.-\mathrm{H}_{2} \mathrm{O}-\mathrm{H}\right]^{-}$ion at $m / z 173$ appeared as the base peak in the $\mathrm{MS}^{2}$ spectrum, due to loss of caffeic acid and a water molecule.

The absence of a fragment ion at $m / z 179$ in the $\mathrm{MS}^{n}$ fragmentation of compound $\mathbf{1}$ indicates that the substitution group is connected to a $5-\mathrm{OH}$ position. The fragment ion at $\mathrm{m} / \mathrm{z} 481$ was produced by the loss of $\mathrm{H}_{2} \mathrm{O}$ ( $\left.18 \mathrm{Da}\right)$.

In $\mathrm{MS}^{3}$ spectrum, were detected fragment ions at $m / z 85,87,93$, $109,111,127$ (base peak), 129, 153 and 173. According to the fragmentation of compound 5-O-caffeoylquinic acid (5-CQA), described by Clifford et al. (2003), in $\mathrm{MS}^{3}$ spectrum the ions $m / z$ 85, 93, 127 and 173 are characteristic of this molecule, which support the idea that we have a substitution in position $5-\mathrm{OH}$. So, $\mathbf{1}$ was identified as 5-O-coumaroylcaffeoylquinic acid and its fragmentation pathway is represented in Scheme 1.

Compound $4\left(t_{R}=5.1 \mathrm{~min}\right)$ was detected overlapped with another peak (described later) and showed a $[\mathrm{M}-\mathrm{H}]^{-}$ion at $m / z$ 353. Its $\mathrm{MS}^{2}$ fragmentation showed a fragment ion at $m / z 191$ (base peak). Comparing its HPLC retention time and $\mathrm{MS}^{n}$ fragmentation pattern with a standard solution of 5-O-caffeoylquinic acid, they were found to be similar. Therefore, 4 was identified as 5-Ocaffeoylquinic acid.

Compound $5\left(t_{\mathrm{R}}=7.0 \mathrm{~min}\right)$ showed a $[\mathrm{M}-\mathrm{H}]^{-}$ion at $m / z 615$. Its $\mathrm{MS}^{2}$ fragmentation showed the loss of $262 \mathrm{Da}$ forming a fragment ion at $m / z$ 353. The MS ${ }^{3}$ spectrum of this ion showed as base peak a fragment ion at $m / z 191$, which indicates a 5-O-caffeoylquinic acid structure. Based on the literature reports (Lin and Harnly, 2008) the fragment of $262 \mathrm{Da}$ is probably composed of a caffeoyl group (162 Da) esterified with a succinyl moiety (100 Da). However, the linkage position of this fragment was not possible to identify based on these MS $^{n}$ data. Therefore, $\mathbf{5}$ was identified as dicaffeoylsuccinylquinic acid.

Compound $10\left(t_{R}=13.0 \mathrm{~min}\right)$ and $11\left(t_{R}=14.6 \mathrm{~min}\right)$ showed a $[\mathrm{M}-\mathrm{H}]^{-}$ion at $\mathrm{m} / \mathrm{z} 515$ and were identified as 3,5-Odicaffeoylquinic acid (3,5-diCQA) and 4,5-O-dicaffeoylquinic acid (4,5-diCQA), respectively. Both isomers gave as base peak, in $\mathrm{MS}^{2}$ spectrum, a [M-H-162 $]^{-}$ion at $m / z 353$ that corresponds to the loss of a caffeyol residue (162 Da). However, their $\mathrm{MS}^{3}$ and $\mathrm{MS}^{4}$ spectra of the $m / z 353$ ions were found to be different. Compound 11 gave as base peak in the $\mathrm{MS}^{3}$ spectrum a fragment ion at $\mathrm{m} / \mathrm{z}$ 173 which indicates the presence of a $4-\mathrm{OH}$ substituted quinic acid. Based on previously reports (Clifford et al., 2003), it is possible to differentiate the 3,4-O-dicaffeoylquinic acid from the 4,5-Odicaffeoylquinic acid since the two isomers differ in the intensity of the $\mathrm{MS}^{2}$ "dehydrated" ion at $m / z 335\left(\left[\mathrm{M}-\mathrm{H}_{2} \mathrm{O}-\mathrm{H}^{+}\right]^{-}\right)$. For 3,4-Odicaffeoylquinic acid, the peak at $m / z 335$ is more intense (ca. $15 \%$ of base peak). While for 4,5-O-dicaffeoylquinic acid this ion is barely detectable ( $<5 \%$ of base peak). The MS ${ }^{2}$ spectrum of 11 showed did not exhibited a secondary ion at $m / z 335$, thus, this compound was identified as 4,5-O-dicaffeoylquinic acid.

The $\mathrm{MS}^{3}$ spectrum of $\mathbf{1 0}$ showed as base peak a fragment ion at $\mathrm{m} / z 191$ ([quinic acid-H $^{-}$) and a fragment ion at $\mathrm{m} / z 179$ (49.3\% of base peak) ([caffeic acid $\left.-\mathrm{H}]^{-}\right)$. Comparing this fragmentation behavior to literature data (Gouveia and Castilho, 2009) 10 was identified as 3,5-O-dicaffeoylquinic acid.

Further comparison with reference standards confirmed the identification proposed.

\subsubsection{Identification of procyanidin compound (2)}

Compound $2\left(t_{\mathrm{R}}=4.3 \mathrm{~min}\right)$ showed a $[\mathrm{M}-\mathrm{H}]^{-}$ion at $\mathrm{m} / \mathrm{z} 577$ characteristics of dimeric procyanidins. The procyanidin $\mathrm{B}$ dimers 


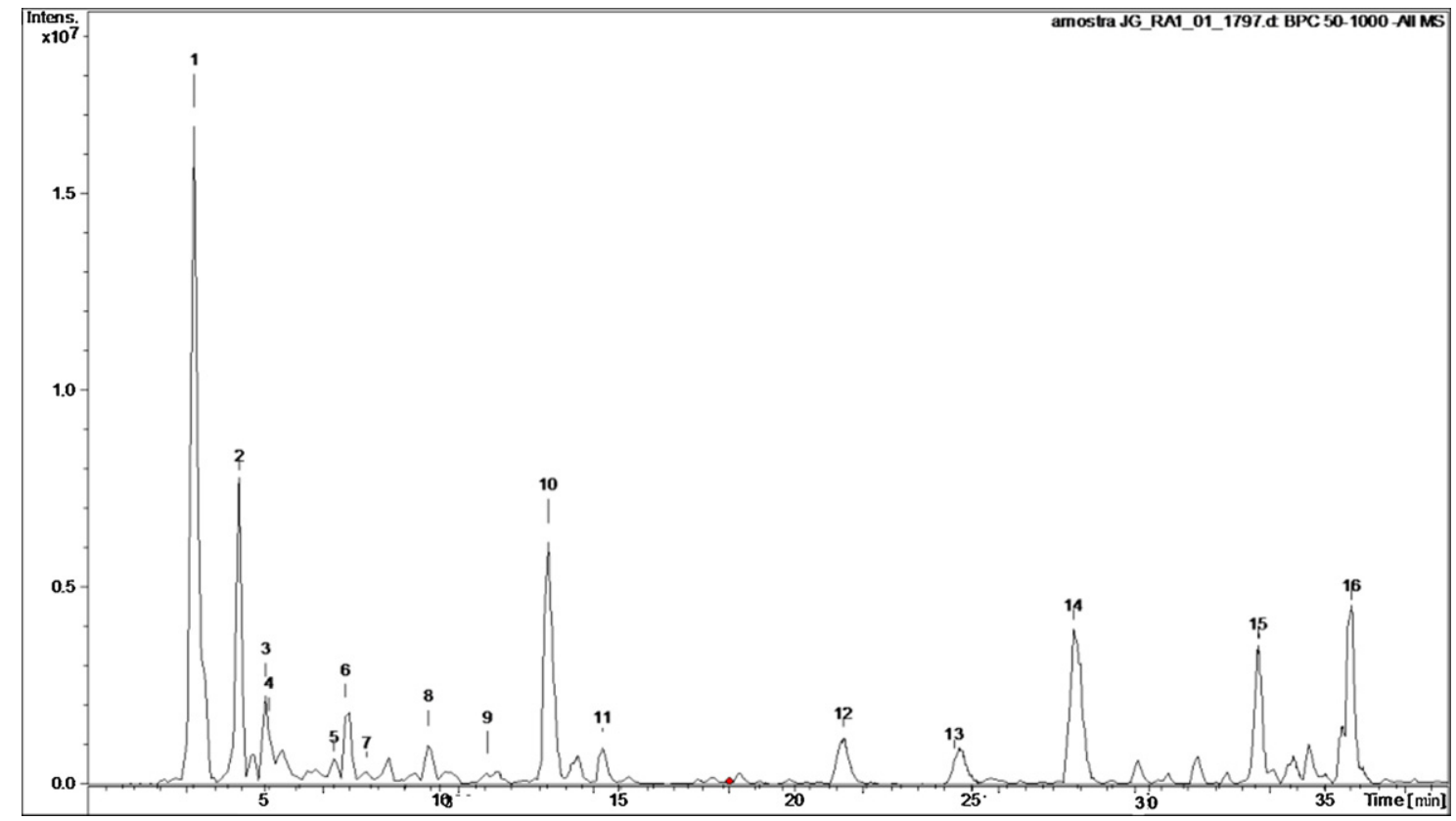

Fig. 1. HPLC-DAD-ESI/MS ${ }^{n}$ analysis of the methanolic extract of Andryala glandulosa spp. varia - HPLC-MS negative ion ESI-MS ${ }^{n}$ base peak chromatogram (BPC) (peak identification according to Table 1).<smiles>OC[C@H]1O[C@H](O)[C@H](O)[C@H](O)[C@H]1O</smiles>

Glucose<smiles>O=C(O)CCC(=O)O</smiles>

Succinic acid<smiles>O=C(O)C1OC(O)C(O)C(O)C1O</smiles>

Glucuronic acid<smiles>OC[C@@H]1O[C@H](O)[C@H](O)[C@H]1O</smiles>

Rhamnose<smiles>O=C(O)C1(O)CC(O)C(O)C(O)C1</smiles>

Quinic acid<smiles>[R]c1cc(/C=C/C(=O)O)ccc1O</smiles>

Coumaric acid $\mathrm{R}=\mathrm{H}$ Caffeic acid $\mathrm{OH}$<smiles>O=c1cc(-c2ccc(O)c(O)c2)oc2cc(O)cc(O)c12</smiles>

\section{Luteolin}

Fig. 2. Chemical structures of phenolic compounds and its substituents in the ethanolic extract of Andryala glandulosa spp. varia. 
Table 1

Characterization of phenolic compounds of the ethanolic extract of flowers in Andryala glandulosa spp. varia by HPLC-DAD-ESI/MS ${ }^{n}$.

\begin{tabular}{|c|c|c|c|c|c|}
\hline Peak No. & $t_{\mathrm{R}}(\min )$ & $\mathrm{UV} \lambda_{\max }(\mathrm{nm})$ & {$[\mathrm{M}-\mathrm{H}]^{-} m / z$} & HPLC-DAD-ESI/MS ${ }^{n} m / z$ (\% base peak) & Identification \\
\hline 1 & 3.0 & 278 & 499.3 & $\begin{array}{l}\mathrm{MS}^{2}[499.3]: 173.0(94.3), 190.9(100), 353.1(13.2), 481.1 \\
(18.7) \\
\text { MS }^{3}[499.3 \rightarrow 190.9]: 85.2(37.9), 87.0(22.5), 93.1(57.3), 109.1 \\
(21.8), 110.9(43.5), 127.0(100), 129.2(45.4), 152.8(17.6), \\
172.9(18.1)\end{array}$ & $\begin{array}{l}5-O- \\
\text { coumaroylcaffeoylquinic } \\
\text { acid }\end{array}$ \\
\hline 2 & 4.3 & 201,261 & 577.3 & $\begin{array}{l}\mathrm{MS}^{2}[577.3]: 391.1(14.6), 409.0(100), 410.0(15.9) \\
\mathrm{MS}^{3}[577.3 \rightarrow 409.0]: 240.9(13.7), 283.0(12.4), 301.0(27.6) \\
373.0(19.6), 391.0(100), 392.0(10.1) \\
\mathrm{MS}^{4}[577.3 \rightarrow 409.0 \rightarrow 391.0]: 204.9(72.0), 240.9(48.0), 246.0 \\
(100), 283.0(44.0)\end{array}$ & Procyanidin \\
\hline 3 & 5.0 & $217,242,325$ & 519.3 & $\begin{array}{l}\text { MS }^{2}[519.3]: 155.0(11.6), 215.0(44.7), 259.0(100), 260.0 \\
(13.6) \\
\text { MS }^{3}[519.3 \rightarrow 259.0]: 155.0(30.1), 215.0(100), 216.0(55.0) \\
\text { MS }^{4}[519.3 \rightarrow 259.3 \rightarrow 215.0]: 155.0(100), 155.9(30.2)\end{array}$ & Unknown \\
\hline $4^{\mathrm{a}}$ & 5.1 & $242,300,325$ & 353 & $\begin{array}{l}\mathrm{MS}^{2}[353]: 191(100) \\
\text { MS }^{3}[353 \rightarrow 191]: 85 \text { (46.1), } 93 \text { (100), } 111 \text { (52.2), } 127 \text { (56.8), } \\
173 \text { (45.7) }\end{array}$ & 5-O-caffeoylquinic acid \\
\hline 5 & 7.0 & $230,291,318$ & 615 & $\begin{array}{l}\text { MS }^{2}[615]: 191(38.6), 353(100) \\
\text { MS }^{3}[615 \rightarrow 353]: 191(100) \\
\text { MS }^{4}[615 \rightarrow 353 \rightarrow 191]: 85(100), 127(69.9), 153(74.4), 173 \\
(94.5)\end{array}$ & $\begin{array}{l}\text { Dicaffeoylsuccinylquinic } \\
\text { acid }\end{array}$ \\
\hline 6 & 7.3 & 230,318 & 471.4 & $\begin{array}{l}\mathrm{MS}^{2}[471.4]: 425.2(100), 426.1(20.9) \\
\mathrm{MS}^{3}[471.4 \rightarrow 425.2]: 175.1(14.7), 201.0(22.7), 219.0(17.9) \\
245.0(34.1), 263.0(100) \\
\mathrm{MS}^{4}[471.4 \rightarrow 425.2 \rightarrow 263.0]: 105.1(18.8), 109.2(28.5), 175.0 \\
(23.2), 176.0(14.8), 201.0(34.4), 216.9(19.7), 219.0(55.6) \\
245.0(100), 246.1(45.5)\end{array}$ & Unknown \\
\hline 7 & 7.9 & 244,326 & 579 & $\begin{array}{l}\mathrm{MS}^{2} \text { [579]: } 285 \text { (100), } 286(11.4) \\
\mathrm{MS}^{3}[570 \rightarrow 285]: 199(71.4), 217 \text { (48.9), } 243(100)\end{array}$ & $\begin{array}{l}\text { Luteolin-7-O-pentoside- } \\
\text { hexoside }\end{array}$ \\
\hline 8 & 9.7 & 245,326 & 447 & $\begin{array}{l}\text { MS }^{2}[447]: 285(100), 286(15.6) \\
\text { MS }^{3}[447 \rightarrow 285]: 175(74.5), 199(100), 217 \text { (91.6), } 241 \text { (40.5), } \\
243(22.0)\end{array}$ & Luteolin-7-O-hexoside \\
\hline 9 & 11.3 & 243,326 & 461 & $\begin{array}{l}\mathrm{MS}^{2}[461]: 285(100), 286(16.5) \\
\operatorname{MS}^{3}[461 \rightarrow 285]: 199(76.2), 217(82.3), 243(100)\end{array}$ & $\begin{array}{l}\text { Luteolin-7-O- } \\
\text { glucuronide }\end{array}$ \\
\hline $10^{\mathrm{a}}$ & 13.0 & $217,243,326$ & 515.2 & $\begin{array}{l}\mathrm{MS}^{2}[515.3]: 353.1(100), 354.0(18.0) \\
\text { MS }^{3}[515.3 \rightarrow 353.1]: 179.0(49.3), 190.9(100) \\
\text { MS }^{4}[515.3 \rightarrow 353.1 \rightarrow 190.9]: 85.2(96.9), 87.1(26.7), 93.2 \\
(81.4), 96.2(11.0), 99.2(23.0), 110.1(16.3), 126.9(44.2), 145.0 \\
(59.1), 152.9(33.5), 171.0(28.0), 172.9(100)\end{array}$ & $\begin{array}{l}3,5 \text { - } O \text {-dicaffeoylquinic } \\
\text { acid }\end{array}$ \\
\hline $11^{\mathrm{a}}$ & 14.6 & $245,295,328$ & 515.2 & $\begin{array}{l}\mathrm{MS}^{2}[515.2]: 173.0(20.7), 179.0(10.1), 202.9(12.4), 353.1 \\
(100), 354.1(15.7) \\
\mathrm{MS}^{3}[515.2 \rightarrow 353.1]: 135.1(23.7), 154.9(15.1), 173.0(100), \\
179.0(86.0), 180.0(11.6), 191.0(59.5) \\
\mathrm{MS}^{4}[515.2 \rightarrow 353.1 \rightarrow 173.0]: 93.1(100), 95.3(11.0)\end{array}$ & $\begin{array}{l}4,5-O \text {-dicaffeoylquinic } \\
\text { acid }\end{array}$ \\
\hline 12 & 21.2 & - & 455.3 & $\begin{array}{l}\mathrm{MS}^{2}[455.3]: 409.1(100), 410.2(19.7) \\
\mathrm{MS}^{3}[455.3 \rightarrow 409.1]: 123.1(12.6), 132.9(13.6), 135.0(21.3) \\
247.0(100), 248.0(18.8), 391.0(10.9) \\
\mathrm{MS}^{4}[455.3 \rightarrow 409.1 \rightarrow 247.0]: 123.0(17.5), 165.1(30.9), 173.0 \\
(26.5), 201.8(15.8), 203.0(100), 204.0(12.0), 219.0(38.1)\end{array}$ & Unknown \\
\hline 13 & 24.5 & - & 457.3 & $\begin{array}{l}\mathrm{MS}^{2}[457.3]: 249.1(11.7), 411.2(100), 412.1(19.0) \\
\mathrm{MS}^{3}[457.3 \rightarrow 411.2]: 249.1(100), 250.1(19.6) \\
\mathrm{MS}^{4}[457.3 \rightarrow 411.2 \rightarrow 249.1]: 205.0(92.5), 206.1(100)\end{array}$ & Unknown \\
\hline $14^{\mathrm{a}}$ & 27.9 & $206,253,346$ & 285.1 & $\begin{array}{l}\text { MS }^{2}[285.1]: 109.0(18.8), 133.0(14.8), 149.0(45.9), 150.9 \\
(70.8), 156.0(13.2), 172.9(68.9), 175.0(100), 189.9(10.6), \\
196.9(11.6), 199.0(99.0), 199.8(24.1), 214.0(76.0), 217.1 \\
(25.0), 217.7(14.0), 241.0(17.4), 242.8(39.3), 243.8(11.7), \\
254.9(47.4), 258.0(30.9), 267.0(19.6), 269.8(14.8) \\
\text { MS }^{3}[285.1 \rightarrow 199.0]: 172.0(100)\end{array}$ & Luteolin \\
\hline 15 & 32.9 & 269 & 327.4 & $\begin{array}{l}\mathrm{MS}^{2}[327.4]: 165.1(22.3), 171.0(86.9), 182.9(13.9), 201.0 \\
(23.1), 209.1(27.5), 211.1(38.2), 221.1(16.8), 229.1(100), \\
239.0(15.2), 247.2(22.4), 291.2(34.7), 309.1(12.0) \\
\text { MS }^{3}[327.4 \rightarrow 229.1]: 85.1(59.2), 126.9(24.8), 165.1(59.2), \\
167.1(33.8), 194.0(96.8), 208.9(100), 211.0(25.5) \\
M^{4}[327.4 \rightarrow 229.1 \rightarrow 208.9]: 166.0(100)\end{array}$ & Unknown \\
\hline 16 & 35.7 & $213,224,297,306$ & 329.4 & $\begin{array}{l}\mathrm{MS}^{2}[329.4]: 171.0(12.8), 183.1(15.9), 209.1(15.5), 211.1 \\
(71.8), 229.1(100), 230.1(15.5), 293.2(17.8), 311.2(20.4) \\
\mathrm{MS}^{3}[329.4 \rightarrow 229.1]: 95.6(21.0), 124.9(20.6), 127.2(38.0), \\
163.0(12.3), 209.0(41.3), 210.9(100) \\
\text { MS }^{4}[329.4 \rightarrow 229.1 \rightarrow 210.9]: 95.2(30.6), 125.0(100)\end{array}$ & Unknown \\
\hline
\end{tabular}

\footnotetext{
a Comparison with a reference standard; - Their UV spectra have not been properly observed due to low intensity.
} 


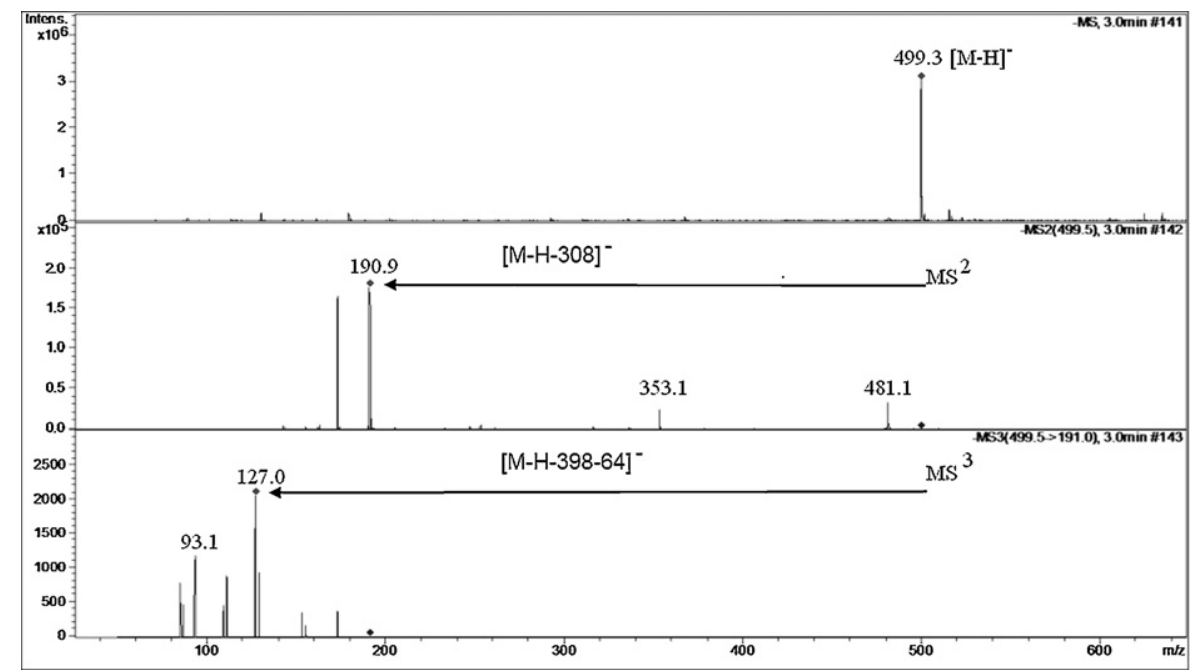

Fig. 3. ESI/MS ${ }^{n}$ negative mode of compound 1. Sequential fragmentation, $\mathrm{MS}^{n}$ ( $n$ up to 3 ) of the ion at $m / z 499$.

consist of eight stereoisomers composed of catechin and epicatechin monomers that can be divided into two subgroups based on their 4-8 or 4-6 linkage (Eng et al., 2003).

However, the fragmentation pattern obtained for this compound was not found reported in the literature, especially concerning the non-observation of the ion $\mathrm{m} / \mathrm{z} 289$ typical of procyanidins B (de Souza et al., 2008; Sun et al., 2007).

The fragmentation in $\mathrm{MS}^{2}$ gave a mass spectrum with a base peak at $m / z 409$ that corresponds to the loss of $\mathrm{C}_{8} \mathrm{H}_{8} \mathrm{O}_{4}(168 \mathrm{Da})$. A fragment at $m / z 391$ was also observed and may correspond to the combined loss of $\mathrm{C}_{8} \mathrm{H}_{8} \mathrm{O}_{4}$ and $\mathrm{H}_{2} \mathrm{O}\left([\mathrm{M}-\mathrm{H}-168-18]^{-}\right) . \mathrm{MS}^{3}$ spectrum contained a base peak ion at $\mathrm{m} / \mathrm{z} 391$ that corresponds to the loss of a molecule of water. The ion at $m / z 373$ (20\% of base peak) corresponds to the loss of two molecules of water (36 Da), the $m / z 241$ (14\%) to loss of $\mathrm{C}_{8} \mathrm{H}_{8} \mathrm{O}_{4}$ and the $m / z 392$ (10\%) occur with the loss of a hydroxyl group. The formation of a fragment ion at $m / z 283$ can be possibly caused by the loss of $\mathrm{C}_{8} \mathrm{H}_{8} \mathrm{O}_{4}(168 \mathrm{Da})$ and $\mathrm{C}_{2} \mathrm{H}_{2} \mathrm{O}$ (42 Da) residues. The ion at $m / z 301$ suggests the loss of a ring $\mathrm{C}_{6} \mathrm{H}_{6} \mathrm{O}_{2}$. In the absence of standard compounds to clarify this structure of this molecule, no further identification was attempted at this point.

\subsubsection{Identification of flavones derivatives ( $\mathbf{7}, \mathbf{8}, \mathbf{9}$ and 14)}

Compound $14\left(t_{\mathrm{R}}=27.9 \mathrm{~min}\right)$ exhibited a $[\mathrm{M}-\mathrm{H}]^{-}$ion at $m / z 285$ and its $\mathrm{MS}^{n}$ fragmentation formed several fragment ions at $m / z 243$ $\left(\left[\mathrm{M}-\mathrm{H}-\mathrm{C}_{2} \mathrm{H}_{2} \mathrm{O}\right]^{-}\right), 241\left(\left[\mathrm{M}-\mathrm{H}-\mathrm{CO}_{2}\right]^{-}\right), 217\left(\left[\mathrm{M}-\mathrm{H}-\mathrm{C}_{3} \mathrm{O}_{2}\right]^{-}\right), 175$

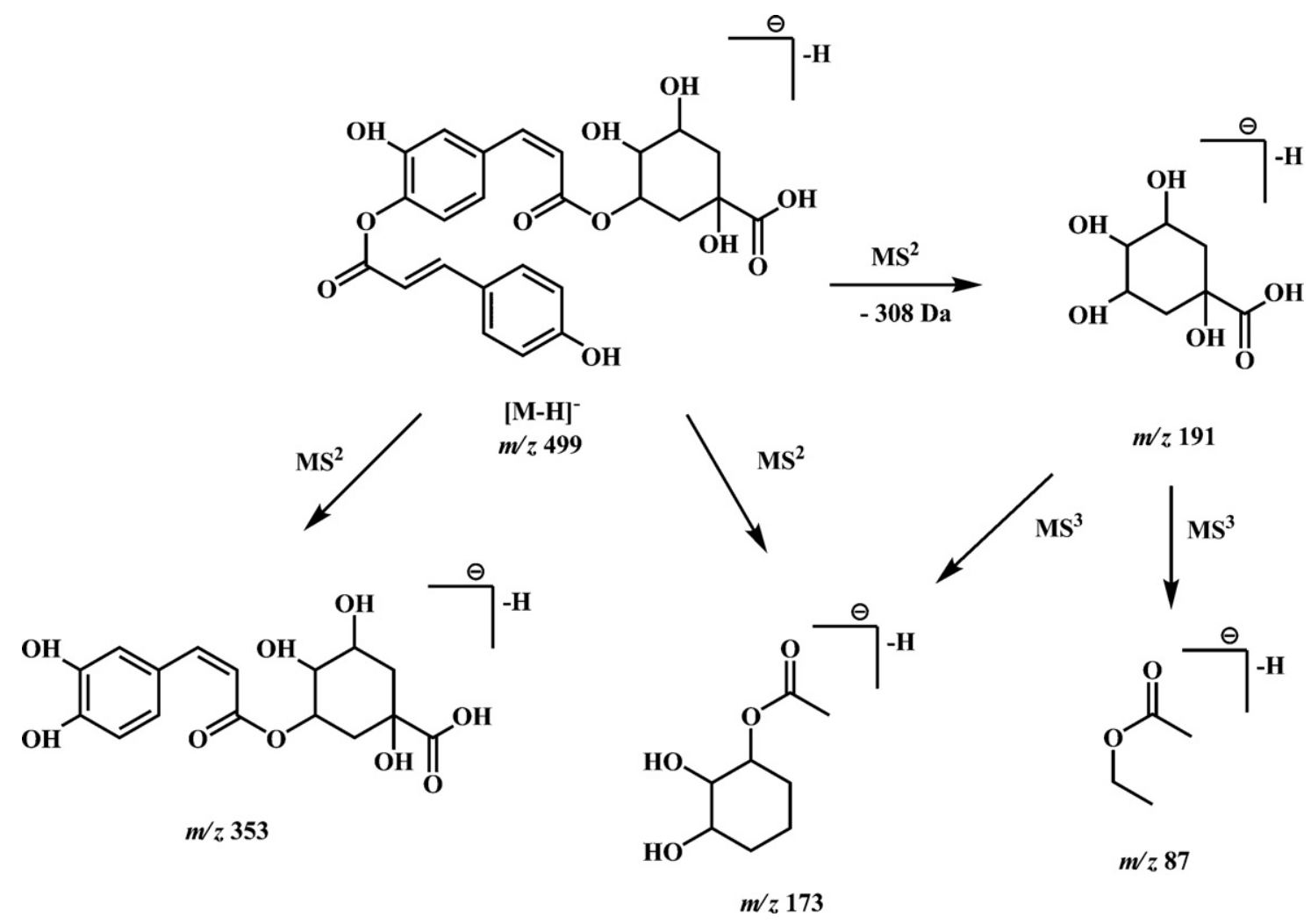

Scheme 1. Proposed fragmentation pathway for compound 1. 
Table 2

Contents of individual phenolic compounds in Andryala glandulosa ethanolic extract ( $\mathrm{mg} / 100 \mathrm{~g}$ of plant material).

\begin{tabular}{|c|c|c|c|c|}
\hline Compound & $5-0$ & CQA3,5-O-diCQA & 4,5-O-diCQA & Total amount \\
\hline Ethanolic extract & $22.40 \pm 0.21$ & $59.69 \pm 1.1$ & $3.81 \pm 0.031$ & $85.90 \pm 1.3$ \\
\hline
\end{tabular}

$\left(\left[\mathrm{M}-\mathrm{H}-\mathrm{C}_{3} \mathrm{O}_{2}-\mathrm{C}_{2} \mathrm{H}_{2} \mathrm{O}\right]^{-}\right)$and $199\left({ }^{1,3} \mathrm{~A}^{-}\right)$. This compound was identified as luteolin by comparison of its $\mathrm{MS}^{n}$ fragmentation pattern with that of a reference standard (data not shown) and literature data (Gouveia and Castilho, 2009).

Compound $7\left(t_{\mathrm{R}}=7.9 \mathrm{~min}\right)$ displayed a $[\mathrm{M}-\mathrm{H}]^{-}$ion at $\mathrm{m} / \mathrm{z} 579$ and under $\mathrm{MS}^{n}$ fragmentation this ion easily loosed a fragment of $294 \mathrm{Da}$ forming the deprotonated aglycone ion, $\mathrm{Y}_{0}{ }^{-}$, at $\mathrm{m} / \mathrm{z} 285$. Fragmentation of this ion formed fragment ions at $m / z 243,199$ and 217, characteristics of luteolin. The $294 \mathrm{Da}$ residue is probably composed of a hexoside (162 Da) and a pentoside (132 Da) group. The favored glycosylation position for flavoinds is the 7-OH. Therefore, compound 7 was identified as luteolin-7-O-pentosidehexoside (Cuyckens and Claeys, 2004).

Compound $8\left(t_{\mathrm{R}}=9.7 \mathrm{~min}\right)$ exhibited a $[\mathrm{M}-\mathrm{H}]^{-}$ion at $\mathrm{m} / z 447$. When submitted to further fragmentation this ion readily eliminated a hexoside residue $(162 \mathrm{Da})$ to produce the deprotonated aglycone ion, $\mathrm{Y}_{0}{ }^{-}$, at $m / z 285$. The $\mathrm{MS}^{3}$ spectrum of the aglycone ion gave fragments ions at $m / z$ 199, 217, 175, 241 and 243 characteristic ions of luteolin as described above. So, compound $\mathbf{8}$ was characterized as luteolin-7-O-hexoside.

Compound $9\left(t_{\mathrm{R}}=11.3 \mathrm{~min}\right)$ showed a $[\mathrm{M}-\mathrm{H}]^{-}$ion at $\mathrm{m} / \mathrm{z} 461$ and its MS ${ }^{2}$ spectrum showed a fragment ion at $m / z 285$ due to the loss of $176 \mathrm{Da}$, probably a glucuronic acid moiety. The $\mathrm{MS}^{3}$ fragmentation of the deprotonated aglycone ion, $\mathrm{Y}_{0}{ }^{-}$, at $m / z 285$ gave ions characteristic of luteolin (Scheme 2). Comparing these data and literature data (Gouveia and Castilho, 2009) 9 was identified as luteolin-7-O-glucuronide.

\subsubsection{Other compounds}

Other peaks, described as compounds 3, 6, 12, 13, 15 and 16, were observed. However, the elucidation of their structures, based solely on UV and $\mathrm{MS}^{n}$ data, could not be completely achieved.

At a retention time of $5.0 \mathrm{~min}$, compound 3 exhibited a $[\mathrm{M}-\mathrm{H}]^{-}$ ion at $m / z$ 519. The MS ${ }^{2}$ spectrum showed an ion at $m / z 259$ from the loss of $260 \mathrm{Da}$. Its $\mathrm{MS}^{n}$ fragmentation gave ions at $m / z 215$ (loss of $44 \mathrm{Da}$, probably $\mathrm{CO}_{2}$ ) and 155 (loss of $60 \mathrm{Da}$ ). It is apparently a dimer but this information is not enough to identify the monomer.

Compound $\mathbf{6}\left(t_{\mathrm{R}}=7.3 \mathrm{~min}\right)$ gave a $[\mathrm{M}-\mathrm{H}]^{-}$ion at $\mathrm{m} / z 471$ and its fragmentation led to formation of a fragment ion at $\mathrm{m} / \mathrm{z} 425$ which corresponds to the loss of $46 \mathrm{Da}$ (probably formic acid). The MS ${ }^{3}$ and $\mathrm{MS}^{4}$ spectra showed ions at $\mathrm{m} / \mathrm{z} 263$ (loss of $162 \mathrm{Da}$, probably a hexoside residue) and $m / z 245$ (loss of $18 \mathrm{Da}$, probably $\mathrm{H}_{2} \mathrm{O}$ ).

Compounds $12\left(t_{R}=21.2 \mathrm{~min}\right)$ and $\mathbf{1 3}\left(t_{\mathrm{R}}=24.5 \mathrm{~min}\right)$, under fragmentation, exhibited a deprotonated molecular ion $[\mathrm{M}-\mathrm{H}]^{-}$at $m / z$ 455 and 457, respectively. Both compounds presented a very similar $\mathrm{MS}^{n}$ pattern and gave the neutral loss of $46 \mathrm{Da}$ (formic acid) in $\mathrm{MS}^{2}$ spectrum, $162 \mathrm{Da}$ (hexoside residue) in $\mathrm{MS}^{3}$, and $44 \mathrm{Da}\left(\mathrm{CO}_{2}\right)$ in $\mathrm{MS}^{4}$ fragmentation.

Compounds $\mathbf{1 5}\left(t_{\mathrm{R}}=32.9 \mathrm{~min}\right)$ and $\mathbf{1 6}\left(t_{\mathrm{R}}=35.7 \mathrm{~min}\right)$, under fragmentation, showed a deprotonated molecular ion $[\mathrm{M}-\mathrm{H}]^{-}$at $\mathrm{m} / \mathrm{z}$ 327 and 329 , corresponding to $\mathrm{C}_{21} \mathrm{H}_{30} \mathrm{O}_{3}$ and $\mathrm{C}_{21} \mathrm{H}_{28} \mathrm{O}_{3}$, respectively. Their $\mathrm{MS}^{2}$ spectra presented an identical base peak ion at $\mathrm{m} / \mathrm{z}$ 229. In $\mathrm{MS}^{3}$ spectra, compound 10 showed a base peak at $\mathrm{m} / z 209$ (loss of $20 \mathrm{Da}$ ) while compound 11 showed a base peak at $\mathrm{m} / \mathrm{z} 211$ (loss of $18 \mathrm{Da}$, probably $\mathrm{H}_{2} \mathrm{O}$ ). In $\mathrm{MS}^{4}$, compounds 15 and 16 showed a based peak at $m / z 166$ (loss of $43 \mathrm{Da}$ ) and $\mathrm{m} / z 125$ (loss of $86 \mathrm{Da}, 2$ times $43 \mathrm{Da}$ ), respectively. Since these compounds show a $[\mathrm{M}-\mathrm{H}]^{-}$ ion very identical (only differ in $2 \mathrm{Da}$ ) and a $\mathrm{MS}^{n}$ very similar, probably the only difference between these compounds is a double bond.
Since these are relatively intense peaks in the chromatogram, further studies will be performed in order to determine their relevance for the antioxidant activity of the extract and to achieve their identification. A compound with $[\mathrm{M}-\mathrm{H}]$ at $m / z 329$ with a similar pattern of fragmentation was detected but not identified in Fagus sylvatica and Betula pendula (Mammela, 2001).

\subsection{HPLC-UV-DAD quantification of caffeoylquinic acids isomers}

The three caffeoylquinic acids detected in the HPLC-ESI/MS ${ }^{n}$ screening were quantified by HPLC-DAD $(\lambda=320 \mathrm{~nm})$ and Table 2 resumes the results obtained.

As so, 3,5-O-dicaffeoylquinic acid is the isomer present in highest amount at $59.69 \pm 1.1 \mathrm{mg} / 100 \mathrm{~g}$ plant. This value represents ca. $69 \%$ of the total CQA compounds quantified.

5-O-dicaffeoylquinic acid level was about half of that found for $3,5-O$-dicaffeoylquinic acid with a value at $22.40 \pm 0.21 \mathrm{mg} / 100 \mathrm{~g}$ dry plant and 4,5-O-dicaffeoylquinic acid was found in very low amounts at $3.81 \pm 0.031 \mathrm{mg} / 100 \mathrm{~g}$ dry plant, ca. $4.44 \%$ of the total amount of CQA isomers quantified.

5-O-dicaffeoylquinic acid was also quantified in Hieracium pilosella L. methanolic extracts (Stanojević et al., 2009) and the values obtained were ca. 10 times higher than those found Andryala flowers. However, the $H$. pilosella extract corresponded to the leaves and roots which are morphological parts, in general, with highest amounts of compounds.

\subsection{Total phenolic content (TPC) and total flavonoid content (TFC)}

The TPC was determined by the Folin-Ciocalteu method which is a rapid, simple and reproducible method widely used and results are shown in Table 3.

The ethanolic extract gave a remarkably higher TPC value when compared to similar plants, values at $621.2 \pm 5.05 \mathrm{mg} \mathrm{GAE} / 100 \mathrm{~g}$. TFC value was also exceptionally high (328.7 $\pm 1.28 \mathrm{mg}$ RUE/100 g). $H$. pilosella, a plant closely related to $A$. glandulosa was recently studied showing values in the order of $105 \mathrm{mg} \mathrm{GAE} / 100 \mathrm{~g}$ and $35 \mathrm{mg}$ RUE/100 g for TPC and TFC respectively (Stanojević et al., 2009).

\subsection{Antioxidant capacities}

Antioxidants can reduce radicals primarily by two mechanisms: single electron transfer (ET) and hydrogen atom transfer (HAT).

The presence of different antioxidant compounds in the plant extracts makes it relatively hard to quantify each antioxidant activity component separately, so the selected method to measure the

Table 3

TPC, TFC, DPPH, ABTS and FRAP assays results for ethanolic extracts from flowers of Andryala glandulosa spp. varia.

\begin{tabular}{ll}
\hline Assay & Ethanol extract \\
\hline Total phenolic content (mg GAE/100 g dried plant) & $621.2 \pm 5.05$ \\
Total flavonoid content (mg RUE/100 g dried plant) & $328.7 \pm 1.28$ \\
DPPH ( $\mu$ mol eq. Trolox/100 g dried plant) & $1271 \pm 10.5$ \\
ABTS ( $\mu$ mol eq. Trolox/100 g dried plant) & $10,049 \pm 139$ \\
FRAP (mmol Fe(II)/mg dried plant) & $7151 \pm 165$ \\
Yield $(\%)$ & 25.2 \\
\hline
\end{tabular}

Values represented as mean $\pm \mathrm{SD}(n=3)$ 

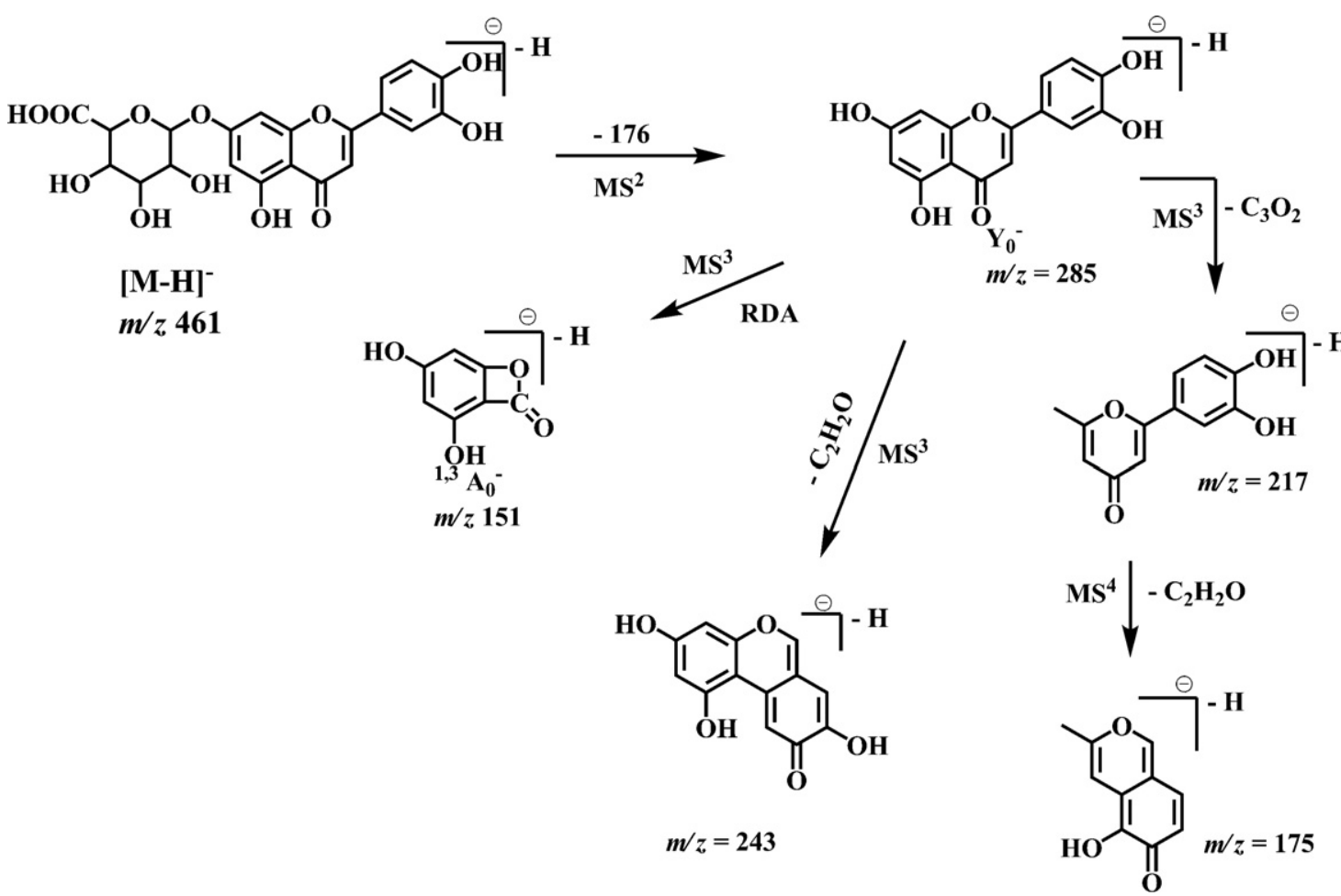

Scheme 2. Proposed fragmentation pathway for compound 9.

antioxidant activity gave results relative to the total antioxidant activity of the whole sample.

The radical scavenging capacity (RSC) of the ethanol extract of the flowers from A. glandulosa was determined by two assays: DPPH and ABTS methods.

In the DPPH assay the methanol extract gave a value at $1271 \pm 10.5 \mu \mathrm{mol}$ eq. Trolox $/ 100 \mathrm{~g}$ plant. While for the ABTS ${ }^{\bullet+}$ assay the value obtained was $10,049 \pm 138.8 \mu$ mol eq. Trolox/100 g plant (Table 3).

The ABTS assay values were higher than the correspondent values by the DPPH method. Higher values in the ABTS assay are mainly due to differences in the sensitivity of the method since ABTS assay measures the antioxidant activity of both hydrophilic and lipophilic antioxidants.

Cai et al. (2004) studied 112 traditional medicinal antioxidant plants (aqueous and alcoholic extracts) using the ABTS method. Comparing alcoholic extracts, A. glandulosa extract is one of the most active plants. Among the Asteraceae plants presented in that study, Chysantheumum morifolium Ramat is the most active with $731.6 \mu \mathrm{mol}$ eq. Trolox $/ 100 \mathrm{~g}$ dry plant, still more than 10 times less active than $A$. glandulosa. Special attention that studies of different labs must be compared in qualitative way since small variations in experimental conditions can affect drastically the results.

In the FRAP method, the yellow $\mathrm{Fe}^{3+}$-TPTZ complex is reduced to the blue $\mathrm{Fe}^{2+}$-TPTZ complex by electron-donating substances, under acidic conditions. Any electron donating substances with a half reaction of lower redox potential than $\mathrm{Fe}^{3+} / \mathrm{Fe}^{2+}-\mathrm{TPTZ}$ will drive the reaction and the formation of the blue complex forward. In this method the extract showed an increase of absorbance over time (Nilsson et al., 2005). A. glandulosa, already confirmed as being a good radical scavenger it was also a good source of compounds with reducing capacity as it can be concluded by the FRAP value at $7151 \pm 165 \mathrm{mmol} \mathrm{Fe}(\mathrm{II}) / \mathrm{mg}$.

Our group published recently a study with Artemisia Argentea alcoholic extracts (Gouveia and Castilho, 2011) using the same antioxidant assays described in this paper and we can conclude that A. glandulosa flowers extracts present the highest antioxidant capacity.

\section{Conclusion}

A. glandulosa grows in rather difficult to reach places, accessible only by narrow and sometimes dangerous footpaths. Despite this and the existence of other similar easier to gather plants, $A$. glandulosa extracts are gaining popularity, reaching the urban natural products shops at high prices. From this study it appears that the absence of potentially harmful lactones may be the key issue for the local collectors preference.

In this study, it was reported for the first time, the high antioxidant capacity associated to the characterization of the phenolic composition of the flowers from A. glandulosa spp. varia.

The results showed that the ethanolic extract was the strongest radical scavenger in both $\mathrm{DPPH}^{\bullet}$ and $\mathrm{ABTS}^{\bullet+}$ assays, while both extracts displayed in some extent good reducing capacity.

The HPLC-DAD-ESI/MS ${ }^{n}$ screening was used to determine the phenolic composition of the ethanolic extract of $A$. glandulosa.

Ten compounds were identified or characterized based on the $\mathrm{MS}^{n}$ fragmentation behavior, UV spectra and HPLC retention time making use of the described rules and published data.

The major compounds found in alcoholic extract were quinic acid and luteolin derivatives. The detection of luteolin derivatives is in good agreement with the high TFC value of this extract.

Three caffeoylquinic acid isomers were quantified and 3,5-O-dicaffeoylquinic acid was present in highest amounts $(59.69 \pm 1.07 \mathrm{mg} / 100 \mathrm{~g}$ of plant) which represents more than $69 \%$ of the amounts of these three compounds.

\section{Acknowledgments}

S.C. Gouveia is grateful to Fundação para a Ciência e Tecnologia (FCT) for a Ph.D. grant SFRH/BD/24227/2005. The 
mass spectrometer used in this work is part of the Portuguese National Mass Spectrometry Network (Contract RNEMREDE/1508/REM/2005) and was purchased in the framework of the National Programme for Scientific Re-equipment, with funds from POCI 2010 (FEDER) and FCT. This research was supported by FCT with funds from the Portuguese Government (Project PEstOE/QUI/UI0674/2011).

The authors wish to acknowledge the contribution of taxonomist Fátima Rocha in plant collection and identification.

\section{References}

Akkol, E.K., Göger, F., Kosar, M., Baser, K.H.C., 2008. Phenolic composition and biological activities of Salvia halophila and Salvia virgata from Turkey. Food Chem. 108, 942-949.

Atoui, A.K., Mansouri, A., Boskou, G., Kefalas, P., 2005. Tea and herbal infusions: their antioxidant activity and phenolic profile. Food Chem. 89, 27-36.

Benzie, I.F.F., Strain, J.J., 1996. The ferric reducing ability of plasma (FRAP) as a measure of "antioxidant power": the FRAP assay. Anal. Biochem. 239, 70-76.

Cai, Y., Luo, Q., Sun, M., Corke, H., 2004. Antioxidant activity and phenolic compounds of 112 traditional Chinese medicinal plants associated with anticancer. Life Sci. 74, 2157-2184.

Clifford, M.N., Johnston, K.L., Knight, S., Kuhnert, N., 2003. Hierarchical scheme for LC-MS $^{n}$ identification of chlorogenic acids. J. Agric. Food Chem. 51, 2900-2911.

Cuyckens, F., Claeys, M., 2004. Mass spectrometry in the structural analysis of flavonoids. J. Mass. Spectrom. 39, 1-15.

de Souza, L.M., Cipriani, T.R., Iacomini, M., Gorin, P.A.J., Sassaki, G.L., 2008. HPLC/ESIMS and NMR analysis of flavonoids and tannins in bioactive extract from leaves of Maytenus ilicifolia. J. Pharm. Biomed. Anal. 47, 59-67.

Eng, E.T., Ye, J., Williams, D., Phung, S., Moore, R.E., Young, M.K., Gruntmanis, U., Braunstein, G., Chen, S., 2003. Suppression of estrogen biosynthesis by procyanidin dimers in red wine and grape seeds. Cancer Res. 63, 8516-8522.

Gaskin, J.F., Wilson, L.M., 2007. Phylogenetic relationships among native and naturalized Hieracium (Asteraceae) in Canada and the United States based on plastid DNA sequences. Syst. Bot. 32, 478-485.

Gouveia, S.C., Castilho, P.C., 2009. Analysis of phenolic compounds from different morphological parts of Helichrysum devium by liquid chromatography with on-line UV and electrospray ionization mass spectrometric detection. Rapid Commun. Mass Spectrom. 23, 3939-3953.
Gouveia, S.C., Castilho, P.C., 2011. Antioxidant potential of Artemisia argentea L'Hér alcoholic extract and its relation with the phenolic composition. Food Res. Int. 44, 1620-1631.

Gouveia, S.C., Castilho, P.C., 2012. Helichrysum monizii Lowe: Phenolic composition and antioxidant potential. Phytochem. Anal. 23, 72-83.

Jardim, R., Sequeira, M.M., 2008. The vascular plants (Pteridophyta and Spermatophyta) of the Madeira and Selvagens archipelagosAçores, Direcção Regional do Ambiente da Madeira and Universidade dos Açores, Funchal and Angra do Heroísmo.

Kisiel, W., Michalska, K., 2001. Sesquiterpenoids and phenolics from Crepis conyzifolia. Naturforsch 56c, 961-964.

Lin, L.-Z., Harnly, J.M., 2008. Identification of hydroxycinnamoylquinic acids of arnica flowers and burdock roots using a standardized LC-DAD-ESI/MS profiling method. J. Agric. Food Chem. 56, 10105-10114.

Mammela, P., 2001. Phenolics in selected European hardwood species by liquid chromatography-electrospray ionisation mass spectrometry. Analyst 126 , 1535-1538.

Marco, J.A., Sanz-Cervera, J.F., Yuste, A., Oriola, M.C., 1994. Sesquiterpene lactones and dihydroflavonols from Andryala and Urospermum species. Phytochemistry $36,725-729$.

Nilsson, J., Pillai, D., Önning, G., Persson, C., Nilsson, Å., Åkesson, B., 2005. Comparison of the 2,2prime-azinobis-3-ethylbenzotiazo-line-6-sulfonic acid (ABTS) and ferric reducing anti-oxidant power (FRAP) methods to asses the total antioxidant capacity in extracts of fruit and vegetables. Mol. Nutr. Food Res. 49, 239-246.

Olsen, H., Aaby, K., Borge, G.I.A., 2009. Characterization and quantification of flavonoids and hydroxycinnamic acids in Curly Kale (Brassica oleracea L. Convar. acephala Var. sabellica) by HPLC-DAD-ESI-MS ${ }^{n}$. J. Agric. Food Chem. 57 2816-2825.

Stanojević, L., Stanković, M., Nikolić, V., Nikolić, L., Ristić, D., Čanadanovic-Brunet, J. Tumbas, V., 2009. Antioxidant activity and total phenolic and flavonoid contents of Hieracium pilosella L. extracts. Sensors 9, 5702-5714.

Sun, J., Liang, F., Bin, Y., Li, P., Duan, C., 2007. Screening non-colored phenolics in red wines using liquid chromatography/ultraviolet and mass spectrometry/mass spectrometry libraries. Molecules 12, 679-693.

Tsao, R., Deng, Z., 2004. Separation procedures for naturally occurring antioxidant phytochemicals. J. Chromatogr. B 812, 85-99.

Turland, N.J., 1994. Flora da Madeira, First ed., London.

Vieira, R., 1992. O interesse das plantas endémicas da Macarronésia, Funchal.

Zheng, W., Wang, S.Y., 2001. Antioxidant activity and phenolic compounds in selected herbs. J. Agric. Food Chem. 49, 5165-5170.

Zidorn, C., Shubert, B., Stuppner, H., 2008. Phenolics as chemosystematic markers in and for the genus Crepis (Asteraceae, Cichorieae). Sci. Pharm. 76, 743-750. 